\title{
Health Services Research on Women Veterans: A Critical Partner on the Road to Patient-Centered Care
}

\author{
David Atkins, MD, MPH \\ Department of Veterans Affairs, Office of Research and Development, Health Services Research and Development Service (10P9H), \\ Washington, DC, USA.
}

J Gen Intern Med 28(Suppl 2):S498-9

DOI: $10.1007 / \mathrm{s} 11606-013-2472-7$

(C) Society of General Internal Medicine 2013

$\mathrm{S}$ ince the lifting of the Congressional legislative cap on women's military participation in 1973, women have had an increasing role in the U.S. military and thus become a growing part of our Veteran population. The pace of that growth, however, was accelerated dramatically by the events of $9 / 11$ and the subsequent conflicts in Afghanistan and Iraq. The challenge facing the healthcare system-how to adjust quickly to the needs of this new patient population - was mirrored in that facing Department of Veterans Affairs (VA) research-how do we build research capacity so we can answer the critical questions for the growing segment of our population who are women? Ten years after the start of the Iraq War, both the delivery of women's health care and the conduct of research on women's health have come a long way in the VA. The number of women seeking care in the VA has doubled in the past decade, while the number of researchers addressing women's health has climbed from 15 in the 1990s to over 200 today. This supplement, our third on women Veterans' health research, is testament to the high quality of work catalyzed by those early efforts.

Now is an opportune time to consider what enabled clinical and research success in VA women's health and to reflect on the challenges and unanswered questions that still await us. None of this success would have been possible without the support from the highest levels in VA and the passionate leadership of the individuals who took the lead for clinical operations and research. Dr. Patricia Hayes, the Chief Consultant of VA Women's Health Services and Dr. Elizabeth (Becky) Yano, the champion for women's health research in VA Health Services Research \& Development (HSR\&D), early on recognized the value of a strong partnership between the clinical and research programs, and women's health research is now a high-level priority in the strategic plans of both offices. In addition, the combination of committed individuals and connected networks can greatly accelerate growth and learning in an emerging field. Under the leadership of Dr. Seth Eisen, the HSR\&D Service established the VA Women's Health Research Consortium and the Women's Health Practice-Based Research Network (http:// www.hsrd.research.va.gov/for_researchers/womens_health/) to develop and execute a research agenda in women's health, nurture a community of researchers, and facilitate recruitment of female patients into multi-site studies. ${ }^{1}$

What have we learned over the past decade that has helped shape both the clinical and research agenda for women Veterans? First, women's experience of military service and war differs from that of men, in ways that have lasting effects on their needs as Veterans. While women are less likely to have been exposed to trauma from combat, one in five women seeking care in the VA report some form of military sexual trauma. ${ }^{2}$ How we treat and study clinical disorders such as post-traumatic stress disorder (PTSD) in women Veterans needs to reflect these stark differences in the types of trauma they have experienced. Care-seeking behavior is also different in women and men-women VA users average more outpatient encounters than their male counterparts, including care for medical and mental health conditions. ${ }^{3}$ Women entering a healthcare system that has traditionally focused on the needs of men faced unique challenges, and the VA moved to establish women's health clinics to address the specific primary care and prevention needs of women, including services such as Pap smears, contraceptive counseling, and mammograms. The fact that women still make up a small minority of the VA population poses challenges to clinicians and researchers both-how can we ensure adequate expertise in clinics serving a small number of women, and how can we ensure a sufficient number of women in research studies? What we have learned in trying to meet the needs of women Veterans has generalizable lessons for how healthcare systems adapt to changing demands (for example, the emergence of hepatitis $\mathrm{C}$ as a major chronic health problem among Vietnamera Veterans) and how systems can ensure care remains patient-centered as the population of patients changes.

We would be wise to remember, however, that our focus on women Veterans fits within a larger goal of understanding and delivering care that is truly patient-centered - that meets the individual clinical needs of the patient in a way that aligns with their preferences and abilities. A wide array 
of HSR\&D research, from research on racial and ethnic disparities to that on aging and complex comorbidities, has revealed how the healthcare system often falls short in meeting the specific needs of certain patient groups. But we need to move beyond simply describing these populations in narrower and narrower slices to incorporate a more complete understanding of the things, that make individual patients unique, so that we can deliver more personalized care. Being a woman has important biological, psychological and socio-cultural effects that shape the health of female Veterans and the medical and non-medical care they receive. But just as they differ in important ways, women Veterans also have much in common with their male peers in what they want and need from their health care - easier access to a range of services, especially for those living in rural areas; the ability to use modern technologies to communicate with their provider; care for musculoskeletal conditions; and high quality, confidential care for mental health problems. Thus, addressing the health and health care of women Veterans can often be achieved in the broader context of patient-centered redesign of healthcare services. Research can reveal how gender factors into a more complete picture of the health problems that any Veteran might develop and point us to better ways to design and deliver care that will address the health needs of all Veterans.

Disclaimer: The opinions in this article are those of the author and do not reflect official policy of the Department of Veterans Affairs or the Federal government.

Corresponding Author: David Atkins, MD, MPH; Department of Veterans Affairs, Office of Research and Development, Health Services Research and Development Service (1OP9H), 810 Vermont Ave NW, Washington, DC 20420, USA (e-mail: David.atkins@va.gov).

\section{REFERENCES}

1. Frayne SM, Carney DV, Bastian LA, Bean-Mayberry B, Sadler A, Klap $\mathbf{R}$, Phibbs CS, Kimerling R, Vogt $\mathbf{D}$, Yee E, Lin J, Yano EM. The VA women's health practice-based research network: amplifying women veterans' voices in VA research. J Gen Intern Med. 2013. doi:10.1007/ s11606-013-2476-3.

2. Kimerling R, Gima $\mathbf{K}$, Smith $\mathbf{M W}$, Street A, Frayne S. The veterans health administration and military sexual trauma. Am J Public Health. 2007;97:2160-6.

3. Frayne SM, Yu W, Yano EM, Ananth L, Iqbal S, Thrailkill A, Phibbs CS. Gender and use of care: planning for tomorrow's veterans health administration. Journal of Women's Health. 2007;16(8): 1188-99. 